\title{
Osmoregulation of Vasopressin Secretion via Activation of Neurohypophysial Nerve Terminals Glycine Receptors by Glial Taurine
}

\author{
Nicolas Hussy, Vanessa Brès, Marjorie Rochette, Anne Duvoid, Gérard Alonso, Govindan Dayanithi, and \\ Françoise C. Moos
}

Laboratoire de Biologie des Neurones Endocrines, Centre National de la Recherche Scientifique (CNRS) Unité Mixte de Recherche 5101, Centre CNRS-Institut National de la Santé et de la Recherche Médicale de Pharmacologie et

d'Endocrinologie, 34094 Montpellier Cedex 5, France

Osmotic regulation of supraoptic nucleus (SON) neuron activity depends in part on activation of neuronal glycine receptors (GlyRs), most probably by taurine released from adjacent astrocytes. In the neurohypophysis in which the axons of SON neurons terminate, taurine is also concentrated in and osmodependently released by pituicytes, the specialized glial cells ensheathing nerve terminals. We now show that taurine release from isolated neurohypophyses is enhanced by hypo-osmotic and decreased by hyper-osmotic stimulation. The high osmosensitivity is shown by the significant increase on only 3.3\% reduction in osmolarity. Inhibition of taurine release by 5-nitro2-(3-phenylpropylamino)benzoic acid, niflumic acid, and 4,4'diisothiocyanatostilbene-2,2'-disulfonic acid suggests the involvement of volume-sensitive anion channels. On purified neurohypophysial nerve endings, activation of strychninesensitive GlyRs by taurine or glycine primarily inhibits the high $\mathrm{K}^{+}$-induced rise in $\left[\mathrm{Ca}^{2+}\right]_{i}$ and subsequent release of vasopressin. Expression of GlyRs in vasopressin and oxytocin ter- minals is confirmed by immunohistochemistry. Their implication in the osmoregulation of neurohormone secretion was assessed on isolated whole neurohypophyses. A 6.6\% hypoosmotic stimulus reduces by half the depolarization-evoked vasopressin secretion, an inhibition totally prevented by strychnine. Most importantly, depletion of taurine by a taurine transport inhibitor also abolishes the osmo-dependent inhibition of vasopressin release. Therefore, in the neurohypophysis, an osmoregulatory system involving pituicytes, taurine, and GlyRs is operating to control $\mathrm{Ca}^{2+}$ influx in and neurohormone release from nerve terminals. This elucidates the functional role of glial taurine in the neurohypophysis, reveals the expression of GlyRs on axon terminals, and further defines the role of glial cells in the regulation of neuroendocrine function.

Key words: glycine receptors; taurine; vasopressin; oxytocin; osmoregulation; glial cells; pituicytes; volume-sensitive $\mathrm{Cl}^{-}$ channels; supraoptic nucleus; neurohypophysis; neurohormone secretion
Vasopressin (VP) and oxytocin (OT) are synthesized by hypothalamic neuroendocrine cells localized in the supraoptic nucleus (SON) and the paraventricular nucleus (PVN). The axons of these neurons terminate in the neurohypophysis in which the neurohormones are secreted into the blood circulation. VP and to a lesser extent OT are involved in the regulation of the body water balance. Accordingly, their release is regulated by the osmotic pressure of extracellular fluid through modulation of the electrical activity of OT and VP neurons (Bourque et al., 1994; Bourque and Oliet, 1997; Hussy et al., 2000). Osmoregulation of these neurons is complex, coming from both osmosensory afferent

\footnotetext{
Received Feb. 22, 2001; revised July 2, 2001; accepted July 5, 2001.

This work was supported in part by Centre National d'Etudes Spatiales Grant 98/7346/793. We thank C. Deleuze, V. Chevaleyre, A. Rabié, and M. G. Desarménien for critical reading of this manuscript and E. Bourinet for kindly providing mibefradil.

Correspondence should be addressed to Nicolas Hussy, Centre National de la Recherche Scientifique Unité Mixte de Recherche 5101, CCIPE, 141 rue de la Cardonille, 34094 Montpellier Cedex 5, France. E-mail: hussy@bacchus.montp.inserm.fr.

V. Brès's present address: Centre National de la Recherche Scientifique Unité Propre de Recherche 1142, Institut de Génétique Humaine, 141 rue de la Cardonille, 34396 Montpellier Cedex 5, France.

M. Rochette's present address: Mayo Clinic, Birdsall Building, 4500 San Pablo Road, Jacksonville, FL 32224.

G. Dayanithi's present address: Institut National de la Santé et de la Recherche Médicale U432, Université Montpellier II, Place E. Bataillon, 34095 Montpellier Cedex 5, France.

Copyright (ㄷ) 2001 Society for Neuroscience $\quad 0270-6474 / 01 / 217110-07 \$ 15.00 / 0$
}

inputs and their intrinsic osmosensitivity. The latter results in part from the presence of stretch-inactivated cationic channels in their membrane, which depolarize and hyperpolarize the neurons exposed to hyper-osmotic and hypo-osmotic medium, respectively (Bourque et al., 1994). We recently provided evidence for an additional mechanism of SON neuron osmosensitivity, which involves glial cells as osmosensory elements (Hussy et al., 2000). SON astrocytes specifically concentrate the amino acid taurine (Decavel and Hatton, 1995) and release it in an osmo-dependent manner through volume-sensitive anion channels (Deleuze et al., 1998; Brès et al., 2000). Taurine is an agonist of strychninesensitive glycine receptors (GlyRs) (Betz et al., 1999), expressed at high level on the soma and proximal dendrites of SON neurons (Hussy et al., 1997). Activation of these ligand-gated $\mathrm{Cl}^{-}$channels mediates part of the in vivo hypo-osmotic inhibition of $\mathrm{VP}$ neuron activity (Hussy et al., 1997). Although direct evidence for glial taurine being the actual endogenous agonist of these receptors is still missing, a number of convergent observations strongly argue in favor of this hypothesis. These include the properties of taurine release (Deleuze et al., 1998), its specificity relative to that of the other potential GlyR agonists (Hussy et al., 1997), as well as the apparent absence of glycinergic afferent input to these neurons (Wuarin and Dudek, 1993; Rampon et al., 1996). This points to a peculiar role of SON astrocytes in the osmoregulation 
of neuronal activity and of GlyRs that would serve another function than mediating neuronal fast synaptic transmission.

In the neurohypophysis, taurine is also selectively accumulated in the pituicytes, the specialized astrocytes surrounding SON and PVN neuron axon terminals, and released during hypo-osmotic stimulation (Pow, 1993; Miyata et al., 1997). Numerous factors are known to modulate hormone release at the level of nerve terminals, which express a variety of neurotransmitter and neuropeptide receptors (Hatton, 1990, 1999; Zhang and Jackson, 1995; Rusin et al., 1997; Sheikh et al., 1998; Troadec et al., 1998; Wilke et al., 1998). However, the effect of taurine on neurohormone secretion has not been studied, and it is not known whether local osmotic regulation of VP or OT release takes place in the neurohypophysis. We report here the hypo-osmotic regulation of depolarization-evoked VP secretion in the neurohypophysis, resulting from the osmo-dependent release of taurine from pituicytes, which activates strychnine-sensitive GlyRs on the nerve terminals to inhibit $\mathrm{Ca}^{2+}$ influx and hormone release.

\section{MATERIALS AND METHODS}

Measurement of taurine release. Neurohypophyses were isolated from adult male Wistar rats killed by decapitation, put in a cold $\left(4^{\circ} \mathrm{C}\right)$ oxygenated Locke's solution [in mM: $137 \mathrm{NaCl}, 5 \mathrm{KCl}, 2 \mathrm{CaCl}_{2}, 2 \mathrm{MgCl}_{2}, 1.2 \mathrm{KH}_{2} \mathrm{PO}_{4}$, 10 HEPES, and 10 glucose, $\mathrm{pH} 7.4(300 \mathrm{mOsm} / \mathrm{l})]$, and carefully isolated from the pars intermedia. Tissues were incubated for $40 \mathrm{~min}$ in a Locke's medium supplemented with $500 \mathrm{~nm}\left[{ }^{3} \mathrm{H}\right]$ taurine (Amersham Pharmacia Biotech, Orsay, France) at $35^{\circ} \mathrm{C}$, rinsed three times, placed in perfusion chambers $\left(250 \mu \mathrm{l}\right.$, one neurohypophysis per chamber) at $35^{\circ} \mathrm{C}$, and perfused at a rate of $250 \mu \mathrm{l} / \mathrm{min}$ with oxygenated Locke's solution. After 20 min rest, perfusate was collected every 2 min with a sample collector (model FC204; Gilson France, Villiers-le-Bel, France). $\left[{ }^{3} \mathrm{H}\right]$ Taurine release was estimated by scintillation counting. Hypo-osmotic media were Locke's solutions, to which the appropriate amount of $\mathrm{NaCl}$ was omitted. The respective control iso-osmotic media were the same solutions to which sucrose was added up to an osmolarity of $300 \mathrm{mOsm} / \mathrm{l}$. Basal release of taurine in iso-osmotic medium was fitted with a monoexponential function, and data were normalized to this fit to express release as percentage of basal release (Deleuze et al., 1998, 2000). Two chambers were systematically used as control, and the effects of the various drugs were always compared with the controls of the same set of experiments. All experiments were realized on at least two different preparations. Analysis was performed with Origin 5.0 software (Microcal Software, Inc., Northampton, MA). Data are given as means \pm SEM.

Measurements of $\left[\mathrm{Ca}^{2+}\right]_{i}$. Neurohypophyses freed from the pars intermedia were homogenized at $37^{\circ} \mathrm{C}$ [in $100 \mu \mathrm{l}$ of a solution containing (in mM): 270 sucrose, 0.1 or 2 EGTA, and 20 HEPES, pH 7.2] and spun at $100 \times g$ for $1 \mathrm{~min}$, and the supernatant was further spun at $2400 \times g$ for $4 \mathrm{~min}$. The final pellet containing highly purified nerve terminals (Cazalis et al., 1987) was resuspended in Locke's solution. Isolated nerve terminals were seeded onto glass cover slips and incubated in Locke's solution containing fura-2 AM (2.5 $\mu \mathrm{M}$; Molecular Probes, Europe, Leiden, The Netherlands) and $0.01 \%$ pluronic acid at room temperature for $1 \mathrm{hr}$. After washing, nerve terminals were perfused at a rate of 100 $\mu \mathrm{l} / \mathrm{min}$ with Locke's or high $(25 \mathrm{~mm}) \mathrm{K}^{+}$solution (Locke's solution with $\mathrm{KCl}$ replacing $\mathrm{NaCl}$ ). Fluorescence measurements of $\left[\mathrm{Ca}^{2+}\right]_{\mathrm{i}}$ were performed with a Zeiss Microscope Photometer System (FFP; Zeiss, Oberkochen, Germany), based on an inverted microscope (Axiovert 100; Zeiss) equipped for epifluorescence (objective, Plan-Neofluar 100 $\times / 1.30$ numerical aperture oil immersion). With fluorescence values corrected for background and dark current, $\left[\mathrm{Ca}^{2+}\right]_{\mathrm{i}}$ was calculated from the ratio between 340 and $380 \mathrm{~nm}$ recordings, after fura- 2 calibration performed as described previously (Dayanithi et al., 1996).

Immunohistochemistry. After deep anesthesia with pentobarbital (300 $\mathrm{mg} / \mathrm{kg}$ ), animals were perfused through the ascending aorta with $100 \mathrm{ml}$ of PBS, pH 7.4, followed by $500 \mathrm{ml}$ of $4 \%$ paraformaldehyde in $0.1 \mathrm{M}$ phosphate buffer, $\mathrm{pH}$ 7.4. The neurointermediate hypophysial lobe and a portion of the spinal cord were dissected and immersed in the same fixative for $8 \mathrm{hr}$. Tissues were cut with a vibratome into $40-\mu \mathrm{m}$-thick sections and rinsed in PBS. Sections were incubated for $48 \mathrm{hr}$ at $4^{\circ} \mathrm{C}$ with a monoclonal antibody against GlyR that recognizes all subunits
(mAb4a, diluted 1:200; Alexis Corp., Läufelfingen, Switzerland), either alone or in combination with a second antibody against either VP (guinea pig polyclonal antibody GHC8103, diluted 1:500; Peninsula Laboratories, Belmont, CA) or OT [rabbit polyclonal antibody obtained from G. Alonso, diluted 1:2000]. After rinsing in PBS, sections were incubated for $1 \mathrm{hr}$ with secondary antibodies against mouse $\operatorname{IgG}$ conjugated with Cy3 (diluted 1:1000; Jackson ImmunoResearch, West Grove, PA) and rabbit or guinea pig IgG conjugated with Alexa 488 (diluted 1:1000; Molecular Probes). After rinsing, sections were mounted in Mowiol (Calbiochem, La Jolla, CA) and observed under a Bio-Rad (Hercules, CA) MRC 1024 confocal laser scanning microscope equipped with a krypton-argon mixed gas laser. Two laser lines emitting at 488 and 568 $\mathrm{nm}$ were used to excite the Alexa 488- and Cy3-conjugated secondary antibodies, respectively. The background noise of each confocal image was reduced by averaging five image inputs. Immunostained structures were studied on single confocal images of 1-2 $\mu \mathrm{m}$ thick. Unaltered digitized images were transferred to a personal computer, and Photoshop (Adobe Systems, San Jose, CA) was used to prepare and print final figures. No fluorescent labeling was detected when omitting to apply the primary antibodies.

Radioimmunoassay. Either purified isolated neurohypophysial nerve terminals obtained as described above (terminals from one-half neurohypophysis per chamber), or isolated whole neurointermediate lobes (one per chamber) were placed in $60 \mu \mathrm{l}$ perfusion chambers at $35^{\circ} \mathrm{C}$ and perfused at a rate of $100 \mu \mathrm{l} / \mathrm{min}$ with oxygenated Locke's solution containing $0.01 \%$ BSA and bacitracin $(170 \mu \mathrm{M})$ to prevent VP degradation (Sladek and Armstrong, 1987). After $1 \mathrm{hr}$ rest, 2.5 min perfusate samples were collected in iced tubes containing $10 \mu \mathrm{l}$ of acetic acid and rapidly frozen. Iso- and hypo-osmotic solutions were prepared as described for taurine release. High $\mathrm{K}^{+}$solutions $(25-50 \mathrm{~mm})$ were obtained by replacing $\mathrm{NaCl}$ by $\mathrm{KCl}$. One hundred microliters (isolated terminals) or $10 \mu \mathrm{l}$ (whole neurohypophyses) of each sample were incubated for 24 $\mathrm{hr}$ at $4^{\circ} \mathrm{C}$ with a VP polyclonal antibody [kindly supplied by Dr. John Bicknell (Babraham Institute, Cambridge, UK)] used at a 1:133,000 dilution in a buffer saline (BS) $(140 \mathrm{~mm} \mathrm{NaCl}, 10 \mathrm{~mm}$ HEPES, and $2 \mathrm{gm} / 1 \mathrm{BSA}$, $\mathrm{pH} 7.3$ ) and then for $31 \mathrm{hr}$ at $4^{\circ} \mathrm{C}$ with $12.5 \mathrm{pM}$ iodinated VP (Amersham Pharmacia Biotech). Bound and free $\left[{ }^{125} \mathrm{I}\right] \mathrm{VP}$ were separated by $15 \mathrm{~min}$ centrifugation at $4000 \times g$ in BS supplemented with $0.5 \%$ activated charcoal and $0.05 \%$ dextran (Sigma, St. Quentin, France). Radioactivity was measured in the pellet by gamma counter and converted to VP concentration according to a standard curve systematically established in parallel.

Drugs. Taurine, glycine, strychnine, Arg-vasopressin, niflumic acid, 4,4'-diisothiocyanatostilbene-2,2'-disulfonic acid (DIDS), tamoxifen, 4-bromophenacyl bromide (pBPB), and ATP-Na were from Sigma. Gabazine, $N$ - phenylanthranylic acid (DPC), and 5-nitro-2-(3-phenylpropylamino)benzoic acid (NPPB) were from Research Biochemicals (Natick, MA). Guanidinoethyl sulfonate (GES) was from Toronto Research Chemicals, and mibefradil was a gift from E. Bourinet (Centre National de la Recherche Scientifique, Montpellier, France).

\section{RESULTS}

\section{Osmo-dependent release of taurine in the neurohypophysis}

The osmo-dependent release of taurine from neurohypophysial pituicytes was estimated on perfused acutely isolated whole neurohypophyses from adult rats, using tritiated taurine as a tracer. Under isotonic conditions (300 mOsm/l), neurohypophyses displayed a low sustained release of taurine, which was reversibly increased by application of hypo-osmotic solutions ranging from 290 to $260 \mathrm{mOsm} / 1$ and decreased by hyper-osmotic stimulation (330 mOsm/1) (Fig. 1). These effects were attributable to variations in osmotic pressure because only the concentration of sucrose was changed in the perfusing solutions, with the ion concentrations being kept constant (see Materials and Methods). The increase in taurine release induced by hypo-osmolarity was dependent on the intensity of the stimulus, with a very high sensitivity: a consistent increase in release $(26 \pm 5 \%$ increase; $n=5)$ was already observed for a $10 \mathrm{mOsm} / 1$ decrease in osmolarity, corresponding to a $3.3 \%$ change in osmotic pressure (Fig. 1). This type of sensitivity was reminiscent of that of taurine release from 
A

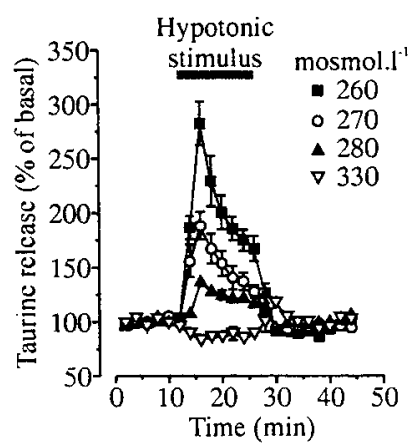

B

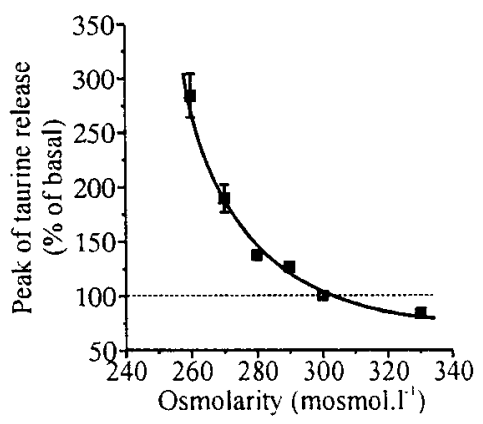

Figure 1. Osmo-dependent release of taurine from the neurohypophysis. $A$, Release of $\left[{ }^{3} \mathrm{H}\right]$ taurine from isolated neurohypophyses was modulated by both hypo-osmotic and hyper-osmotic stimuli. Each trace is the average of 5-12 measurements from at least three different experiments. Note the sustained release induced by small stimulus. $B$, Relationship between the peak of taurine release and the osmolarity of the perfusing solution, showing the high osmosensitivity of release. Error bars are shown when exceeding the size of the symbols. Solid line is a Boltzmann fit of the data.

SON astrocytes (Deleuze et al., 1998, 2000). Release evoked by greater osmotic changes showed a transient component that has been shown in other systems to reflect cell volume regulation (Pasantes-Morales and Shousboe, 1997).

Basal release was strongly enhanced in the presence of $300 \mu \mathrm{M}$ of the taurine transporter inhibitor GES (from $219 \pm 14$ to $468 \pm$ $44 \mathrm{dpm} ; n=6$ each), indicative of a constant reuptake of taurine, but GES did not prevent release evoked by a $280 \mathrm{mOsm} / 1$ hypoosmotic stimulus $(39 \pm 6$ vs $33 \pm 2 \%$ increase in the absence and presence of GES, respectively; $n=6$ each; data not shown). Therefore, the taurine transporter does not mediate release of taurine. The pharmacological properties of taurine release were then studied in the continuous presence of GES to increase the sensitivity of the measurements of drug effects. Both basal and hypotonicity evoked-release were inhibited by classical blockers of anion channels, such as NPPB, niflumic acid, DIDS, and high concentrations of extracellular ATP (Fig. 2), arguing for the involvement of volume-sensitive anion channels, as seen in the SON (Deleuze et al., 1998; Brès et al., 2000). Blockade of evoked release reached $52 \pm 11(50 \mu \mathrm{M} \mathrm{NPPB}), 47 \pm 8(100 \mu \mathrm{M}$ niflumic acid), $70 \pm 4$ (1 mm DIDS), and $34 \pm 5 \%$ (10 mm ATP) (Fig. 2C). On the other hand, release of taurine was totally insensitive to a variety of compounds that block volume-activated anion channels in other preparations (Nilius et al., 1997a,b), such as tamoxifen $(30 \mu \mathrm{M}), \mathrm{pBPB}(50 \mu \mathrm{M})$, mibefradil $(30 \mu \mathrm{M})$, or DPC $(300 \mu \mathrm{M})$ (Fig. $2 C$ ). This pharmacological profile is similar, although not identical, to that reported in the SON. The main differences are the lower sensitivity to ATP and the total absence of blockade by DPC in the neurohypophysis, the latter inhibiting taurine release in the SON with an $\mathrm{IC}_{50}$ of $280 \mu \mathrm{M}$ (Brès et al., 2000). Such a difference was seen in parallel experiments on SON and neurohypophysis using the same batch of DPC.

\section{Taurine-activated GlyRs on neurohypophysial nerve terminals}

To check for a possible action of taurine on nerve terminals, those were isolated from neurohypophysis using a differential centrifugation method (Cazalis et al., 1987), and their activity was monitored by spectrofluorimetry using the $\mathrm{Ca}^{2+}$ indicator fura-2. Because an inhibitory effect may be manifest only when the terminals are for-
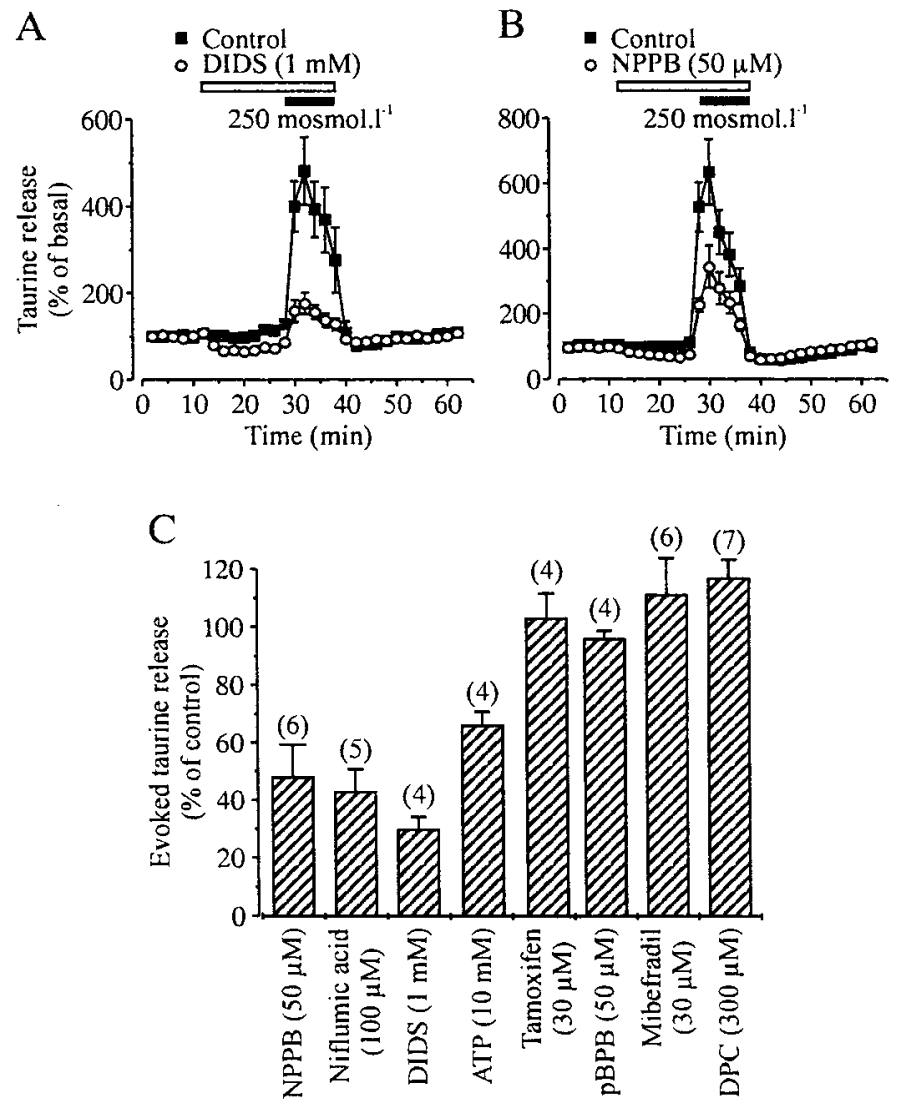

Figure 2. Pharmacological properties of taurine release. $A, B$, Both basal release and that evoked by a hypotonic stimulus are blocked by the anion channel antagonists DIDS $(A)$ and NPPB $(B)$. $C$, Pharmacological profile of taurine release evoked by a $250 \mathrm{mOsm} / 1$ hypotonic stimulus. Inhibition was estimated as described previously (Brès et al., 2000). Number of observations are indicated above the bars.

merly excited, the effect of taurine was tested both in resting conditions and on the $\mathrm{Ca}^{2+}$ entry through voltage-activated $\mathrm{Ca}^{2+}$ channels evoked by a depolarizing high $\mathrm{K}^{+}$solution (Brethes et al., 1987). A moderate concentration of $\mathrm{K}^{+}(25 \mathrm{~mm})$ was chosen to allow inhibitory currents to modulate $\mathrm{Ca}^{2+}$ channel activation. A $10 \mathrm{sec}$ application of this high $\mathrm{K}^{+}$solution induced a transient increase in intracellular $\mathrm{Ca}^{2+}$ concentration $\left(\left[\mathrm{Ca}^{2+}\right]_{\mathrm{i}}\right)$ that went from $154 \pm 10$ to $631 \pm 37 \mathrm{nM}(n=28)$. Application of taurine $(0.5 \mathrm{~mm})$ did not affect resting $\left[\mathrm{Ca}^{2+}\right]_{\mathrm{i}}$ level but strongly and reversibly inhibited the increase in $\left[\mathrm{Ca}^{2+}\right]_{\mathrm{i}}$ evoked by depolarization (Fig. $3 A$ ). On average, inhibition by taurine was $65 \pm 5 \%$ (Fig. $3 C$ ). The effect of taurine was inhibited by $69 \pm 11 \%(n=6)$ when it was coapplied with the GlyR antagonist strychnine $(1 \mu \mathrm{M})($ Fig. $3 A, C)$. Because taurine can also activate $\mathrm{GABA}_{\mathrm{A}}$ receptors, albeit with a lower potency (Hussy et al., 1997), and because these receptors are expressed on neurohypophysial nerve terminals (Zhang and Jackson, 1995), we tested the effect of the $\mathrm{GABA}_{\mathrm{A}}$ receptor antagonist gabazine. Gabazine (3 $\mu \mathrm{M}$ ) was unable to prevent the inhibitory effect of taurine (Fig. $3 B, C)$. Preapplication of $20 \mu \mathrm{M}$ glycine also inhibited the depolarization-induced $\left[\mathrm{Ca}^{2+}\right]_{\mathrm{i}}$ rise $(76 \pm 3 \%$ inhibition) (Fig. $3 D, E)$, and this effect was sensitive to $1 \mu \mathrm{M}$ strychnine, with a $71 \pm 13 \%$ block of glycine action $(n=4)$ (Fig. $3 D, E)$. Therefore, taurine and glycine activate GlyRs on neurohypophysial nerve terminals to reduce the depolarization-evoked $\mathrm{Ca}^{2+}$ influx.

Inhibition of $\mathrm{Ca}^{2+}$ influx should result in inhibition of hormone secretion (Cazalis et al., 1987; Stuenkel and Nordmann, 1993). 

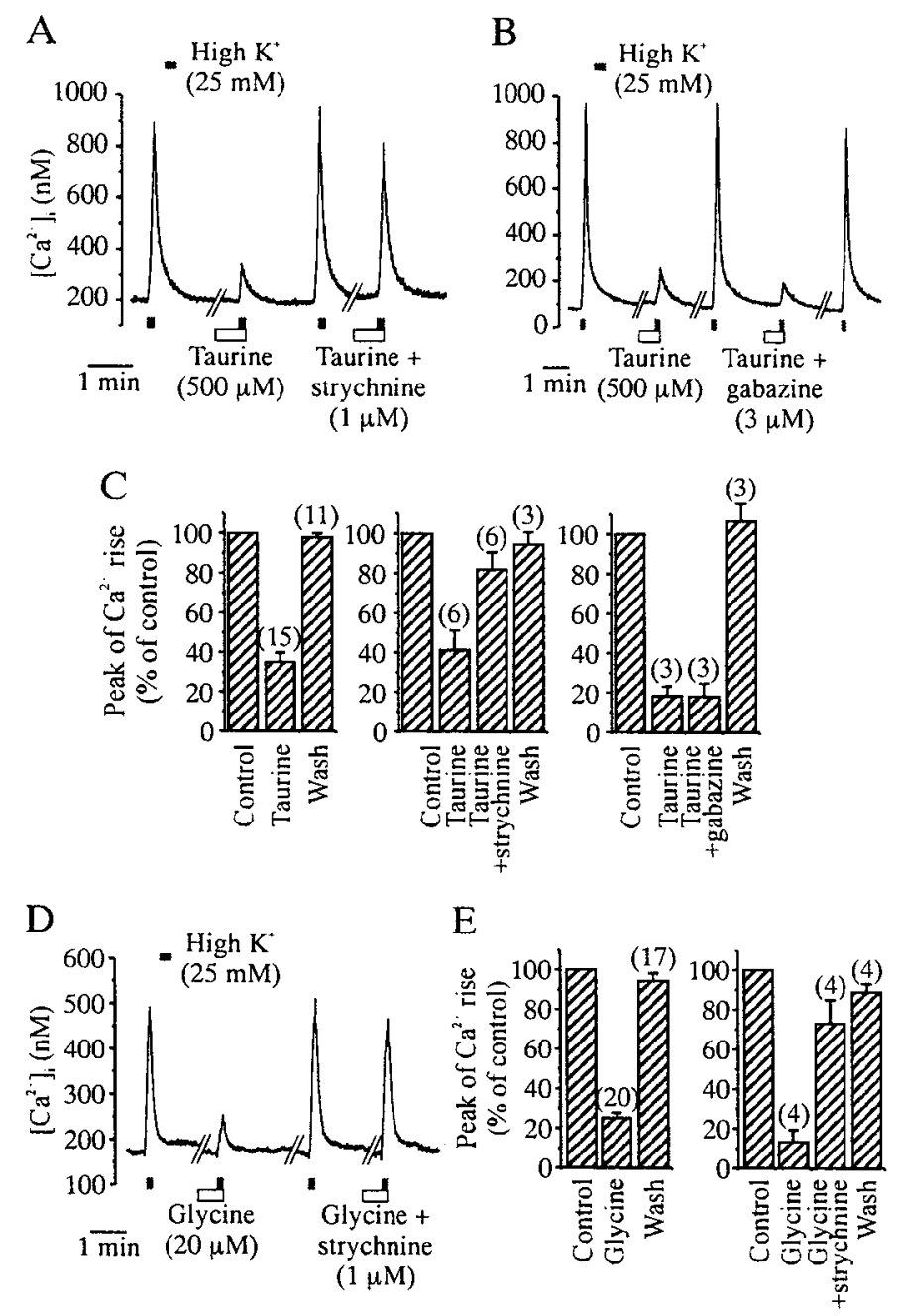

Figure 3. Taurine activates GlyRs on acutely isolated neurohypophysial nerve terminals. $A$, The $\left[\mathrm{Ca}^{2+}\right]_{\mathrm{i}}$ rise induced by a $10 \mathrm{sec}$ application of a high $\mathrm{K}^{+}$solution is inhibited in a strychnine-sensitive manner by taurine (preapplied for $30 \mathrm{sec}$ and coapplied with high $\mathrm{K}^{+}$). B, The $\mathrm{GABA}_{\mathrm{A}}$ receptor antagonist gabazine does not prevent the inhibitory action of taurine. $C$, Mean values of the inhibitory effect of taurine (left), its blockade by strychnine (middle), and lack of effect of gabazine (right). Numbers of observations are indicated above the bars. D, Glycine also inhibits high $\mathrm{K}^{+}$-induced $\left[\mathrm{Ca}^{2+}\right]_{\mathrm{i}}$ transients, and this effect is blocked by strychnine. $E$, Mean values of the inhibitory effect of glycine (left) and its blockade by strychnine (right).

This was verified by measuring VP release from purified isolated neurohypophysial nerve terminals, using radioimmunoassay. $\mathrm{Re}$ lease could be evoked consistently by a $5 \mathrm{~min}$ application of 25 $\mathrm{mm} \mathrm{K}^{+}$, which increased basal release 2.5 -fold to 3.5-fold (Fig. 4), going on average from $40 \pm 2$ to $107 \pm 3 \mathrm{pg} / \mathrm{min}(n=16)$. A $5 \mathrm{~min}$ preincubation with $0.5 \mathrm{~mm}$ taurine strongly inhibited high $\mathrm{K}^{+}$evoked release, with a peak release in the presence of taurine of only $48 \pm 3 \mathrm{pg} / \mathrm{min}(n=6)$ (Fig. $4 B$ ), corresponding to an $82 \%$ inhibition. This inhibitory effect of taurine was primarily prevented when it was coapplied with $1 \mu \mathrm{M}$ strychnine, with evoked release reaching then $99 \pm 6 \mathrm{pg} / \mathrm{min}(n=6)$ (Fig. $4 C)$.

\section{Immunohistochemical visualization of GlyRs in the neurohypophysis}

The presence of GlyRs in the neurohypophysis was confirmed by immunohistochemistry, using a monoclonal antibody recognizing all subunits of GlyR (mAb4a). Intense GlyR immunostaining was
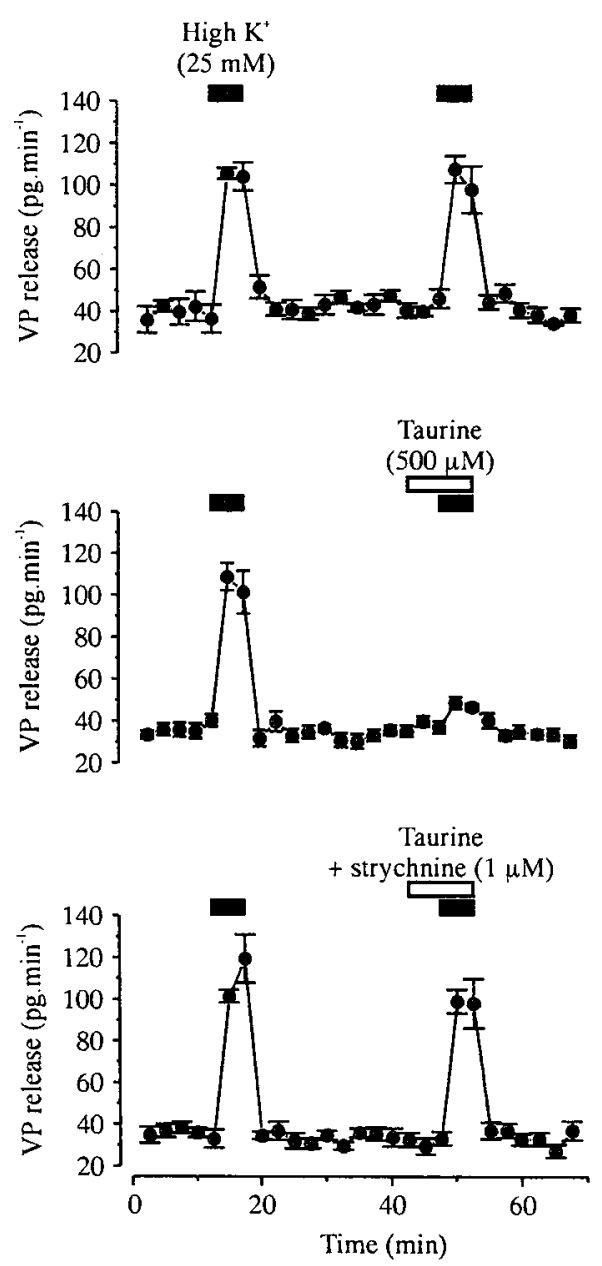

Figure 4. Taurine inhibits VP release on isolated neurohypophysial nerve terminals via activation of GlyRs. A 5 min application of a high $\mathrm{K}^{+}$ solution evokes an increase in VP release $(t o p ; n=4)$, which is strongly inhibited in the presence of taurine (preapplied for $5 \mathrm{~min}$ and coapplied with high $\mathrm{K}^{+}$; middle; $\left.n=6\right)$. Taurine-induced inhibition is prevented in the presence of strychnine (bottom; $n=6$ ).

detected both within the gray matter regions of spinal cord (data not shown) and throughout the neurohypophysis (Fig. 5A). Examination of double-immunostained sections under confocal microscopy further indicated that, within the neurohypophysis, the large majority of GlyR immunostaining was associated with VPor OT-immunopositive axonal structures of various size (Fig. $5 \mathrm{C}-\mathrm{H})$, including small axonal endings and large preterminal dilatations (also known as Herring bodies) (Hatton, 1999). Noteworthy is the observation that, in contrast to VP terminals, some OT-immunopositive nerve endings were not labeled with the GlyR antibody.

\section{Taurine- and GlyR-dependent osmoregulation of VP release in the neurohypophysis}

The results described above suggested that glial taurine and GlyRs could be involved in the osmotic regulation of neurohormone release. This was investigated by measuring VP release by radioimmunoassay from isolated whole neurohypophyses, in which glial-axon contacts should still be functional. To prevent depletion of intracellular taurine, a low concentration of taurine (1 $\mu \mathrm{M}$, lower than normal blood concentration) (Huxtable, 1992) was added to all extracellular solutions. VP release was evoked by 

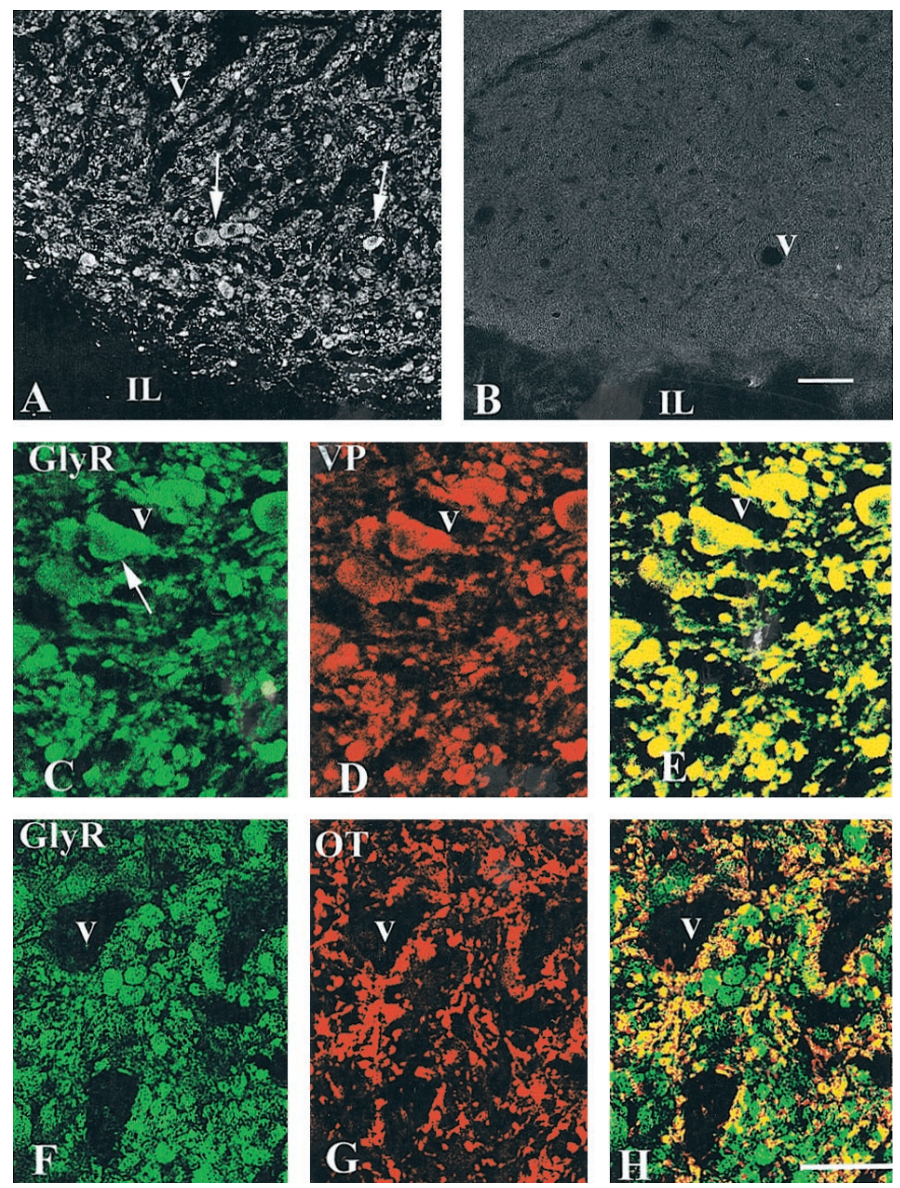

Figure 5. Immunohistochemical detection of GlyRs in the neurointermediate lobe. $A$, Intense immunostaining for the GlyR antibody $\mathrm{mAb} 4 \mathrm{a}$ is associated with axon-like structures localized in the neurohypophysis, both the small axon terminals and the large preterminal swellings called Herring bodies (arrows). Note the absence of staining in the intermediate lobe $(I L)$. $B$, No labeling is detected when the primary antibody is omitted. $C-H$, Double immunostaining for GlyR $(C, F)$ and either VP $(D)$ or OT $(G)$, with superimposed images shown in $E$ and $H$. The majority of GlyR immunostaining in the neurohypophysis colocalizes with axon terminals and Herring bodies (arrows) immunolabeled for either VP or OT (colocalization appears in yellow in $E$ and $H$ ). Note that, in contrast to VP axons, a number of OT axons are devoid of GlyR immunostaining (red structures in $H$ ). $V$, Blood vessels. Scale bars (shown in $B$ ): $A, B, 150 \mu \mathrm{m}$; (shown in $H$ ) $C-H, 75 \mu \mathrm{m}$.

a depolarizing high $\mathrm{K}^{+}$solution $(50 \mathrm{~mm})$. This concentration of $\mathrm{K}^{+}$evoked a consistent, robust increase in $\mathrm{VP}$ release from neurohypophysis (from $237 \pm 18$ to $726 \pm 150 \mathrm{pg} / \mathrm{min}$, corresponding to a threefold increase; $n=7$ ) (Fig. 6) but was still primarily smaller than the ninefold maximal stimulation observed with $100 \mathrm{~mm} \mathrm{~K}^{+}$(data not shown), thus allowing to study the effects of modulatory factors. Basal VP release was not affected by a $20 \mathrm{~min}$ application of a $20 \mathrm{mOsm} / 1$ hypo-osmotic solution, corresponding to a $6.6 \%$ decrease in osmolarity $(216 \pm 21 \mathrm{pg} /$ $\min ; n=9$ ) (Fig. 6A). To quantify and compare evoked release, we considered the amount of VP released during 5 min taken in the middle of the application of the high $\mathrm{K}^{+}$solution and normalized it to basal release measured during an equivalent period before stimulation. High $\mathrm{K}^{+}$-evoked release was significantly inhibited by preapplication of the hypo-osmotic medium, decreasing from $306 \pm 26$ to $191 \pm 19 \%$ of basal release $(n=9 ; p<$ 0.005 , unpaired Student's $t$ test), which corresponded to a $56 \%$

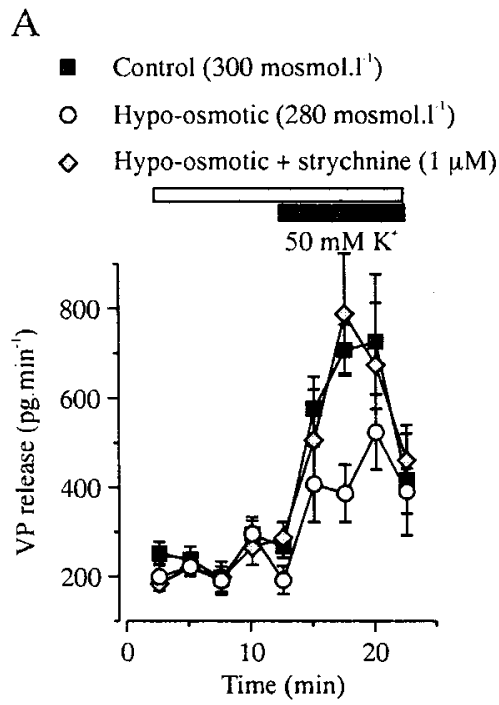

B
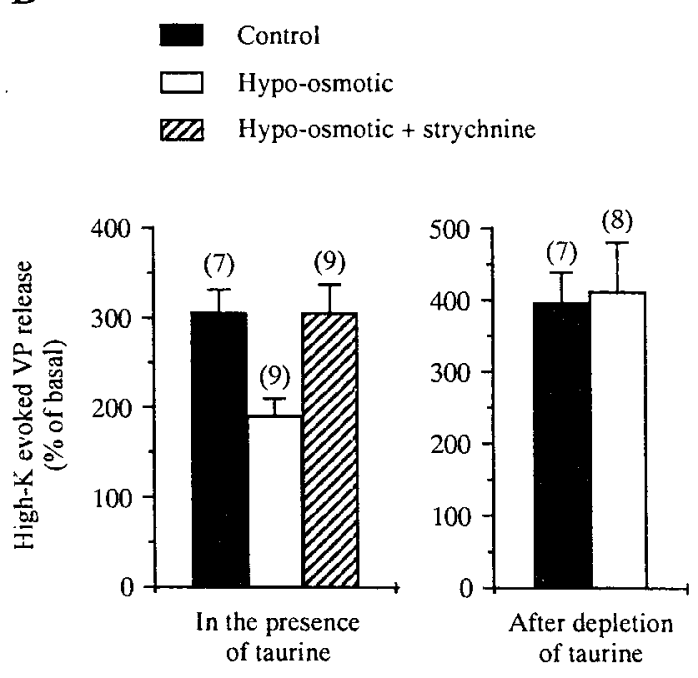

Figure 6. Hypo-osmotic regulation of VP release from isolated neurohypophysis involves GlyRs and requires the presence of taurine. $A$, Release evoked by high $\mathrm{K}^{+}(10 \mathrm{~min})$, but not basal release, is antagonized by a $20 \mathrm{mOsm} / 1$ hypotonic stimulus (preapplied for $20 \mathrm{~min}$ and coapplied with high $\mathrm{K}^{+}$). Each curve is the mean of seven to nine measurements. This inhibition is blocked in the presence of strychnine. Taurine $(1 \mu \mathrm{M})$ was added to all media to preserve the intracellular taurine level. $B$, Mean values of evoked release of VP and strychnine-sensitive blockade by hypotonic stimulus in the presence of $1 \mu \mathrm{M}$ extracellular taurine (left). A $2.5 \mathrm{hr}$ pretreatment with $1 \mathrm{~mm}$ GES in the absence of extracellular taurine to deplete taurine from the tissue totally prevents the inhibitory effect of the hypotonic stimulus (right).

inhibition (Fig. 6). Inhibition by hypo-osmolarity was completely prevented when $1 \mu \mathrm{M}$ strychnine was added to the hypo-osmotic solution $(305 \pm 32 \%$ of basal; $p<0.01)$ (Fig. 6). Therefore, the inhibitory effect of the hypo-osmotic stimulus on the depolarizationevoked release of VP mainly involves activation of GlyRs.

To verify that taurine is indeed the endogenous agonist of GlyRs in hypotonic conditions, neurohypophyses were perfused for $2.5 \mathrm{hr}$ in the absence of extracellular taurine and the presence of $1 \mathrm{~mm}$ of the taurine transport inhibitor GES. Such treatment was performed to partially deplete intracellular taurine from pituicytes (Morán et al., 1994). GES was then washed out for $30 \mathrm{~min}$ to prevent any direct action of GES on VP release, and the effect of 
hypo-osmotic stimulus was tested. In these conditions, VP release evoked by high $\mathrm{K}^{+}(395 \pm 44 \%$ of basal) was no longer inhibited by the hypo-osmotic solution (411 $\pm 69 \%$ of basal) (Fig. 6B). Therefore, the strychnine-dependent inhibition of evoked VP release requires a high level of intracellular taurine, identifying the endogenous activator of GlyRs.

\section{DISCUSSION}

We demonstrate here that neurohormone secretion within the neurohypophysis is subject to local osmo-dependent regulation. This regulatory process involves the release of glial taurine during hypo-osmotic stimulation through volume-sensitive anion channels. Taurine then inhibits evoked hormone secretion via the activation of GlyRs present on neurohypophysial nerve terminals. This mechanism is strikingly similar to that hypothesized previously in the SON and as so validates and extends this model of osmoregulation (Hussy et al., 2000). Taurine- and GlyRdependent osmoregulation of neuroendocrine activity therefore occurs both at the level of the soma and dendrites of magnocellular neurons, in the SON, and at the level of their axon terminals, in the neurohypophysis. Moreover, this report constitutes the first description of the functional expression of GlyRs on an axon terminal, which serves the atypical function of mediating a slow, nonsynaptic, glia-to-neuron transmission. The high osmosensitivity of taurine and VP releases constitutes a strong indication that such a process actually takes place during physiological variations of osmotic pressure.

\section{Taurine release}

We showed that release of taurine is induced by hypo-osmotic stimulus in the neurohypophysis. Because taurine is selectively concentrated in the pituicytes that ensheathe the nerve terminals (Pow, 1993; Miyata et al., 1997), release likely comes from this glial compartment. In the SON, selective accumulation of taurine by astrocytes (Decavel and Hatton, 1995) has been correlated clearly to a pure glial origin of released taurine (Deleuze et al., 1998). Release of taurine in the neurohypophysis is highly sensitive to even small changes in osmotic pressure. Decrease of release by hyper-osmotic stimulus indicates a sustained osmo-dependent release in isotonic conditions. Release was not antagonized by the taurine transporter inhibitor GES but was blocked by various $\mathrm{Cl}^{-}$channel blockers, indicative of the implication of volume-sensitive anion channels, as seen in most cell preparations (Strange and Jackson, 1995; Nilius et al., 1997a; Pasantes-Morales and Schousboe, 1997). The properties of taurine release in the neurohypophysis are mostly similar to those described in the SON (Deleuze et al., 1998; Brès et al., 2000). One difference is the lower sensitivity to ATP in the neural lobe, but this could be attributable to a greater degradation of ATP. Indeed, whereas SON astrocytes are readily accessible to applied drugs because of their location at the ventral side of the nucleus (Hatton, 1999), ATP will have to penetrate the complex structure of the neurohypophysis to access the pituicytes, being then more exposed to ectonucleotidases. More striking is the absence of effect of DPC in the neurohypophysis, although this compound blocks efficiently release in the SON (Brès et al., 2000). This could mean that SON astrocytes and neurohypophysial pituicytes express a different subtype of volume-sensitive anion channels, but for a clear conclusion to be drawn, we will have to wait for the knowledge of the exact site of action of the blocker (Ballatori et al., 1995).

\section{GlyRs on neurohypophysial nerve terminals}

Taurine activates strychnine-sensitive GlyRs on nerve terminals isolated from neurohypophysis. Large expression of GlyRs in both VP and OT terminals (although possibly larger in VP than OT terminals) was confirmed by immunohistochemistry. Activation of these receptors leads to opening of $\mathrm{Cl}^{-}$channels and results in an inhibition of the depolarization-evoked $\left[\mathrm{Ca}^{2+}\right]_{\mathrm{i}}$ rise, which has been shown previously to depend exclusively on $\mathrm{Ca}^{2+}$ entry through voltage-activated $\mathrm{Ca}^{2+}$ channels (Brethes et al., 1987). As expected from the close relationship between $\mathrm{Ca}^{2+}$ entry and neurohormone release (Cazalis et al., 1987; Stuenkel and Nordmann, 1993), GlyR activation by taurine also blocks depolarization-evoked release of VP from purified nerve terminals. The $\mathrm{Cl}^{-}$concentration in neurohypophysial terminals in situ has been estimated to be $20 \mathrm{~mm}$ from measurements of $\mathrm{GABA}_{\mathrm{A}}$ receptor responses (Zhang and Jackson, 1995), yielding an equilibrium potential for $\mathrm{Cl}^{-}$ions $\left(\mathrm{E}_{\mathrm{Cl}}\right.$ of $\left.-48 \mathrm{mV}\right)$ slightly more depolarized than the resting potential of the terminals (Zhang and Jackson, 1995; Branshaw et al., 1998). Activation of a $\mathrm{Cl}^{-}$conductance will thus depolarize the terminals but not sufficiently to activate voltage-dependent $\mathrm{Na}^{+}$or $\mathrm{Ca}^{2+}$ currents. Despite this depolarizing influence, it will result in an inhibition of the terminal excitability. In the case of high $\mathrm{K}^{+}$-evoked $\mathrm{Ca}^{2+}$ entry in isolated terminals, activation of $\mathrm{Ca}^{2+}$ channels is the mere consequence of the depolarizing action of high $\mathrm{K}^{+}$, because it is not blocked by inhibition of $\mathrm{Na}^{+}$channels by TTX (G. Dayanithi, unpublished observation). Because activation of the GlyR $\mathrm{Cl}^{-}$current will lower the depolarization evoked by high $\mathrm{K}^{+}$by pulling the membrane potential toward $\mathrm{E}_{\mathrm{Cl}}$, it will reduce the level of activation of $\mathrm{Ca}^{2+}$ channels, thus accounting for the inhibition of $\mathrm{Ca}^{2+}$ entry. The mechanism of inhibition in situ is, however, different, as shown for $\mathrm{GABA}_{\mathrm{A}}$ receptors, which activation inhibits $\mathrm{Na}^{+}$-dependent spike propagation into neurohypophysial nerve terminals mainly through the voltage-dependent inactivation of axonal $\mathrm{Na}^{+}$channels consecutive to the $\mathrm{Cl}^{-}$ current-induced depolarization (Zhang and Jackson, 1995; Branshaw et al., 1998). A similar consequence of GlyR activation can reasonably be expected.

\section{Implication of GlyR and taurine in the osmoregulation of VP release}

Finally, we showed the inhibition of neurohypophysial VP release by moderate hypo-osmotic stimulus. This effect depends on activation of GlyRs, further implying the receptors in the osmoregulation of neurosecretory activity. Therefore, inhibition of VP secretion by a hypo-osmotic stimulus probably results from the decreased $\mathrm{Ca}^{2+}$ influx induced by activation of GlyR $\mathrm{Cl}^{-}$currents. Because GlyRs can be visualized in both VP and OT terminals in situ and because all isolated terminals express functional GlyRs, such regulation likely applies to OT release as well. However, the detection of some OT terminals not labeled with the GlyR antibody may suggest a lower impact on OT release. Basal, nonstimulated VP secretion is unaffected by hypotonic stimulus or by the blockade of GlyRs by strychnine, despite the increased release of taurine. This observation can be explained by the activity independence of basal hormone release from nerve endings, which is not blocked by removal of external $\mathrm{Ca}^{2+}$ (Cazalis et al., 1987), by chelating intracellular $\mathrm{Ca}^{2+}$ with BAPTA (Stuenkel and Nordmann, 1993) or by blocking $\mathrm{Na}^{+}$channels with TTX (G. Dayanithi, unpublished observation). Therefore, basal release should not be affected by changes in membrane potential or resistance and thus by activation of the $\mathrm{Cl}^{-}$conductance. 
Removal of this regulatory mechanism by depletion of taurine clearly identifies glial taurine as the endogenous activator of GlyRs, in agreement with the lack of detection of glycine in the neurohypophysis (Pow, 1993) and our previous inference from data on the osmoregulation of SON neuron activity (Hussy et al., 2000). Taurine is thus released by glial cells under such osmotic conditions in a sufficient amount to activate GlyRs, as hypothesized previously (Hussy et al., 1997, 2000; Hatton, 1999) based on the high concentration gradient for taurine (a few tens of millimolar inside cells vs at most a few tens of micromolar in the extracellular fluid) (Kimelberg et al., 1990; Huxtable, 1992; Martin, 1992), the reduced extracellular space by hypo-osmolarityinduced cell swelling, and the apparent affinity of GlyRs for taurine ( $\mathrm{EC}_{50}$ of $\sim 400 \mu \mathrm{M}$ in SON neurons) (Hussy et al., 1997). Pituicytes and SON astrocytes therefore act as sensory elements, releasing in an osmo-dependent manner a glia-to-neuron transmitter, taurine. The role of GlyRs as receptors for slow transmission of glial information is quite uncommon for ionotropic receptors. However, this peculiar function may not be restricted to the hypothalamo-neurohypophysial system and could explain the failure to detect glycinergic synaptic transmission in some brain neurons expressing GlyRs (Kaneda et al., 1995). Extrasynaptic activation of GlyRs by endogenous taurine has also been reported in developing cortical neurons (Flint et al., 1998). Whether the implication of GlyRs in the osmoregulation of neuronal electrical and secretory activities is a common mechanism or is specifically related to the particular involvement of SON neurons in the regulation of water balance has still to be determined.

Osmoregulation of neuroendocrine function is a highly complex process, which was known to result from the integration of the osmotic information coming from multiple osmoreceptors located both inside and outside the nervous system, as well as from the osmosensitivity of magnocellular neurons within the SON and PVN (Bourque et al., 1994; Hussy et al., 2000). Our data show that osmoregulation also takes place in the neurohypophysis, acting at the last stage of the hypothalamo-neurohypophysial system, the axon terminals, to directly modulate secretion of neurohormones. Osmoregulation of SON neuron activity involves both neuronal mechanoreceptors and the glial taurine-GlyR system (Hussy et al., 2000). It will be of interest to know whether mechanoreceptors are also present on neurohypophysial nerve terminals to complement regulation by GlyRs in a manner similar to that observed in the SON.

\section{REFERENCES}

Ballatori N, Truong AT, Jackson PS, Strange K, Boyer JL (1995) ATP depletion and inactivation of an ATP-sensitive taurine channel by classic ion channel blockers. Mol Pharmacol 48:472-476.

Betz H, Kuhse J, Schmieden V, Laube B, Kirsch J, Harvey RJ (1999) Structure and functions of inhibitory and excitatory glycine receptors. Ann NY Acad Sci 868:667-676.

Bourque CW, Oliet SHR (1997) Osmoreceptors in the central nervous system. Annu Rev Physiol 59:601-619.

Bourque CW, Oliet SHR, Richard D (1994) Osmoreceptors, osmoreception, and osmoregulation. Front Neuroendoc 15:231-274.

Branshaw JL, Hsu S-F, Jackson MB (1998) Membrane excitability and secretion from peptidergic nerve terminals. Cell Mol Neurobiol 18:45-63.

Brès V, Hurbin A, Duvoid A, Orcel H, Moos FC, Rabié A, Hussy N (2000) Pharmacological characterization of volume-sensitive, taurine permeable anion channels in rat supraoptic glial cells. Br J Pharmacol 130:1976-1982.

Brethes D, Dayanithi G, Letellier L, Nordmann JJ (1987) Depolarizationinduced $\mathrm{Ca}^{2+}$ increase in isolated neurosecretory nerve terminals measured with fura-2. Proc Natl Acad Sci USA 84:1439-1443.

Cazalis M, Dayanithi G, Nordmann JJ (1987) Hormone release from isolated nerve endings of the rat neurohypophysis. J Physiol (Lond) 390:55-70.

Dayanithi G, Widmer H, Richard P (1996) Vasopressin-induced intra- cellular $\mathrm{Ca}^{2+}$ increase in isolated rat supraoptic cells. J Physiol (Lond) 490:713-727.

Decavel C, Hatton GI (1995) Taurine immunoreactivity in the rat supraoptic nucleus: prominent localization in glial cells. J Comp Neurol 354:13-26.

Deleuze C, Duvoid A, Hussy N (1998) Properties and glial origin of osmotic dependent release of taurine from rat supraoptic nucleus. J Physiol (Lond) 507:463-471.

Deleuze C, Duvoid A, Moos FC, Hussy N (2000) Tyrosine phosphorylation modulates the osmosensitivity of volume-dependent taurine efflux from glial cells of the rat supraoptic nucleus. J Physiol (Lond) 523:291-299.

Flint AC, Liu X, Kriegstein AR (1998) Nonsynaptic glycine receptor activation during early neocortical development. Neuron 20:43-53.

Hatton GI (1990) Emerging concepts of structure-function dynamics in adult brain: the hypothalamo-neurohypophysial system. Prog Neurobiol 34:437-504.

Hatton GI (1999) Astroglial modulation of neurotransmitter/peptide release from the neurohypophysis: present status. J Chem Neuroanat 16:203-222.

Hussy N, Deleuze C, Pantaloni A, Desarménien MG, Moos F (1997) Agonist action of taurine on glycine receptors in rat supraoptic magnocellular neurones: possible role in osmoregulation. J Physiol (Lond) 502:609-621.

Hussy N, Deleuze C, Desarménien MG, Moos FC (2000) Osmotic regulation of neuronal activity: a new role for taurine and glial cells in a hypothalamic neuroendocrine structure. Prog Neurobiol 62:113-134.

Huxtable RJ (1992) Physiological actions of taurine. Physiol Rev 72:101-163

Kaneda M, Farrant M, Cull-Candy SG (1995) Whole-cell and singlechannel currents activated by GABA and glycine in granule cells of the rat cerebellum. J Physiol (Lond) 485:419-435.

Kimelberg HK, Goderie SK, Higman S, Pang S, Waniewski RA (1990) Swelling-induced release of glutamate, aspartate, and taurine from astrocyte cultures. J Neurosci 10:1583-1591.

Martin DL (1992) Synthesis and release of neuroactive substances by glial cells. Glia 5:81-94.

Miyata S, Matsushima O, Hatton GI (1997) Taurine in rat posterior pituitary: localization in astrocytes and selective release by hypoosmotic stimulation. J Comp Neurol 381:513-523.

Morán J, Maar TE, Pasantes-Morales H (1994) Impaired cell volume regulation in taurine deficient cultured astrocytes. Neurochem Res 19:415-420

Nilius B, Eggermont J, Voets T, Buyse G, Manolopoulos V, Droogmans G (1997a) Properties of volume-regulated anion channels in mammalian cells. Prog Biophys Mol Biol 68:69-119.

Nilius B, Prenen J, Kamouchi M, Viana F, Voets T, Droogmans G (1997b) Inhibition by mibefradil, a novel calcium channel antagonist, of $\mathrm{Ca}^{2+}$ - and volume-activated $\mathrm{Cl}^{-}$channels in macrovascular endothelial cells. Br J Pharmacol 121:547-555.

Pasantes-Morales H, Schousboe A (1997) Role of taurine in osmoregulation in brain cells: mechanisms and functional implications. Amino Acids 12:281-292.

Pow DV (1993) Immunocytochemistry of amino-acids in the rodent pituitary using extremely specific, very high titre antisera. J Neuroendoc 5:349-356.

Rampon C, Luppi PH, Fort P, Peyron C, Jouvet M (1996) Distribution of glycine immunoreactive cell bodies and fibers in the rat brain. Neuroscience 75:737-755.

Rusin KI, Giovannucci DR, Stuenkel EL, Moises HC (1997) $\kappa$-opioid receptor activation modulates $\mathrm{Ca}^{2+}$ currents and secretion in isolated neuroendocrine nerve terminals. J Neurosci 17:6565-6574.

Sheikh SP, Feldthus N, Orkild H, Göke R, McGregor GP, Turner D, Møller M, Stuenkel EL (1998) Neuropeptide Y2 receptors on nerve endings from the rat neurohypophysis regulate vasopressin and oxytocin release. Neuroscience 82:107-115.

Sladek CD, Armstrong WE (1987) $\gamma$-aminobutyric acid antagonists stimulate vasopressin release from organ-cultured hypothalamoneurohypophyseal explants. Endocrinology 120:1576-1580.

Strange K, Jackson PS (1995) Swelling-activated organic osmolyte efflux: a new role for anion channels. Kidney Int 48:994-1003.

Stuenkel EL, Nordmann JJ (1993) Intracellular calcium and vasopressin release of rat isolated neurohypophysial nerve endings. J Physiol (Lond) 468:335-355.

Troadec J-D, Thirion S, Nicaise G, Lemos JR, Dayanithi G (1998) ATP-evoked increases in $\left[\mathrm{Ca}^{2+}\right]_{\mathrm{i}}$ and peptide release from rat isolated neurohypophysial terminals via a $\mathrm{P}_{2 \times 2}$ purinoceptor. J Physiol (Lond) 511:89-103.

Wilke RA, Hsu SF, Jackson MB (1998) Dopamine D4 receptor mediated inhibition of potassium current in neurohypophysial nerve terminals. J Pharmacol Exp Ther 284:542-548.

Wuarin J-P, Dudek FE (1993) Patch-clamp analysis of spontaneous synaptic currents in supraoptic neuroendocrine cells of the rat hypothalamus. J Neurosci 13:2323-2331.

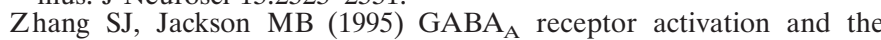
excitability of nerve terminals in the rat posterior pituitary. J Physiol (Lond) 483:583-595. 